\author{
S. M. Shenouda \\ M. M. Moustafa \\ H. S. El-Kilani \\ L. B. Kamar
}

http://dx.doi.org/10.21278/brod69209

ISSN 0007-215X

eISSN 1845-5859

\title{
THE MOST ECONOMICAL CONFIGURATION OF PUSHED BARGE CONVOY SYSTEM THROUGH CAIRO-ASWAN WATERWAY
}

UDC 629.55:629.5.015.26:629.5.076:282.263.1

Professional paper

\begin{abstract}
Summary
In the recent years, as a result of the economical situation in Egypt, fuel price is rapidly increased. Consequently, the cost of cargo transport is also increased. Therefore, the aim of the present paper is to check the feasibility of a pushed barge convoy system working through Cairo-Aswan waterway as an alternative mean of cargo transport in order to encourage the transport companies to transport their cargoes through river Nile which is considered the cheapest transport mode in Egypt.

In this paper, the current situation of the river transport and the characteristics of the Egyptian inland waterways network are reviewed and investigated to identify the navigation problems and constraints which affect the navigation through Cairo-Aswan waterway. The basic concept of ship controllability is reviewed to clarify the maneuver characteristics of a pushed barge convoy system in shallow waterways. Also, different configurations for pushed barge convoy system are proposed and the required power of each configuration is calculated using a specially developed computer program.

A technical and operational measure called transport efficiency is used as a criterion to get the most economical configuration of the desired pushed barge convoy system. Finally, a comparison between the pushed barge convoy system and the existing river transport means in Egypt is made to clarify the feasibility of using pushed barge convoy system through Cairo-Aswan waterway.
\end{abstract}

Key words: $\quad$ Barge Convoy System; Shallow Waterways; River Nile; Transport Efficiency

\section{Introduction}

Transport substantially shapes the growth and development of countries specially, from economic point of view. Although, Egypt enjoys a $1530 \mathrm{~km}$ long stretch of the river Nile, river transport has been sorely neglected compared to the other transport modes. This sector failed to account for more than $1 \%$ of total freight services (roads possessed the lion's share with $93 \%$ and railways followed with 6\%) [1]. That is due to the following reasons: 
1. Interaction in the responsibilities between the ministry of transport and the ministry of irrigation,

2. The river transport facilities have been grossly neglected for many years. Also, many vessels are not adequately equipped so they cannot travel at night,

3. Many vessels are unable to navigate year-round, since the water levels vary in accordance with the old Nile flood season.

4. Many transport companies prefer land transport due to its reliability and door to door service.

In other countries, river transport accounts for a significantly larger share of freight services. In Netherlands the figure is $34 \%$, in Belgium it is $26 \%$ and in Luxemburg it is $14 \%$ [1]. Nowadays, to sustain and enhance the economic growth and vitality, the Egyptian government has decided to emphasize making better use of river transport through supporting the efforts of river transport authority (RTA) to complete its infrastructure projects. Moreover, transport companies intended to increase the volume of the annual transported cargo through the Nile for the following reasons:

1. River transport is considered an important solution to overcome the congestion problems on the Egyptian motorways.

2. According to the Egyptian river transport authority, river transport is considered to be an environmentally-friendly and a safer mode of transport compared to railway and road (trucks on highways) transport modes [1].

3. River transport will have a competitive edge in terms of costs, especially as oil price subsidies are gradually phased out. This is mainly due to economies of scale (one barge with a capacity of 1,500 tons can transfer more than 50 trucks).

By studying the different means of river transport worldwide, it was found that the pushed barge convoy system is the most effective and progressive system of transport with minimal environmental problems. Therefore, the aim of the present paper is finding the most economical configuration of a pushed barge convoy system working through CairoAswan waterway and checking its feasibility.

\section{Pushed barge convoy system}

The concept of pushed barge convoy consists of a pusher boat with one or more nonpropelled barges. This concept is widely used in Europe and United State of America (USA), especially in the Danube, Elbe and Mississippi rivers [2]. From the economical point of view, more barges being used at one time to transport large quantity of goods seem to be more efficient [2]. Also, it has a lower maintenance \& repair and docking costs. Moreover, the possibility of disengaging the pusher boat reduces the risk of total loss in case of collision, grounding or other serious accidents and consequently reduces the insurance cost [3]. In addition to the above mentioned advantages of the pushed barge convoy system, it is characterized by a higher exploitation time since push boat does not have to wait for loading and unloading operations. Therefore, we will study the feasibility of using a pushed barge convoy system for cargo transport through Cairo-Aswan waterway.

\subsection{Configurations of pushed barge convoy systems}

To understand and differentiate between the different configurations of a pushed barge convoy system, a naming system in the form " $\mathrm{nmPB}$ " is used. Where, PB refers to pushed barge convoy system; $\mathrm{n}$ and $\mathrm{m}$ refer to the numbers of barge columns and rows, respectively. Fig.1 shows naming system of 9 pushed barge convoy systems with different configurations [2]. 


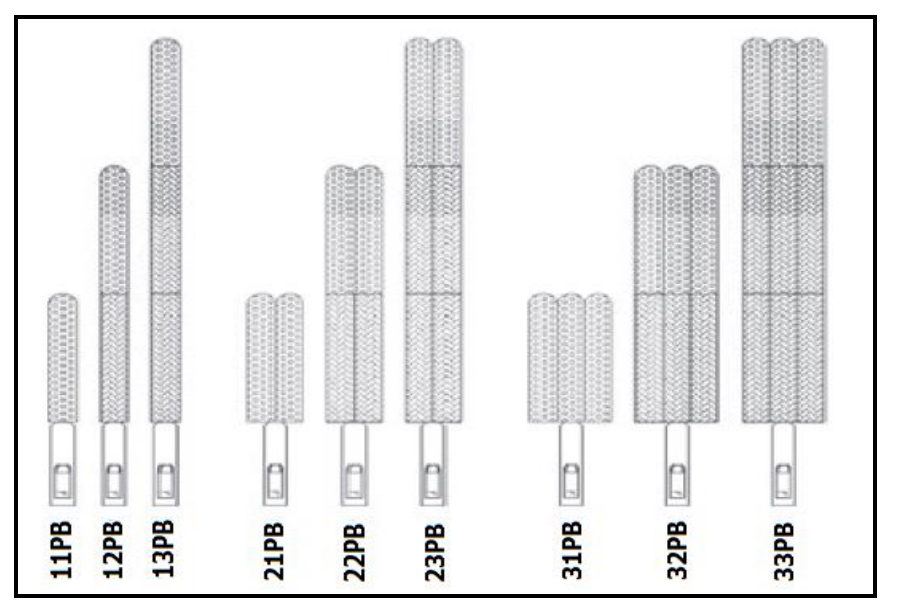

Fig. 1 Naming system of different pushed barge convoy systems [2]

\subsection{Controllability of pushed barge convoy systems}

Controllability is a very complex and important subject and represents an essential consideration in the design of any floating structure. It covers all aspects related to a ship's trajectory, speed and orientation at sea as well as in shallow waters where positioning and course keeping are of particular concern. It is usually divided into three areas; course keeping, maneuvering and speed changing. For conventional ships, course keeping and manoeuvring may tend to work against each other [4].

Performance of pushed barge convoy systems is affected by water depth, channel restrictions and interference with nearby units or obstacles. Therefore, controllability of pushed barge convoy systems is one of the most important considerations facing the naval architect and involves compromises with the other characteristics of the convoy. Many solutions are obtained by comparison with the characteristics of the previously examined designs. In other cases, experimental techniques, theoretical analyses and rational design practices must all come into play to assure adequacy.

In 2008, K. K. King et al [2] carried out an experimental work about manoeuvring simulations of pusher barge convoy systems and model tests were performed at the Hiroshima University Towing Tank on 9 different configurations with 1:50 model scale. In the experiments two types of barges were used; leading barge was always a rake barge and box barges are between the rake barge and the pusher boat. Each configuration was tested at the corresponding full-scale speed of $12.964 \mathrm{~km} / \mathrm{h}$ and full-scale draft of $2.74 \mathrm{~m}$. The results showed that, for the same number of barges, pushed barge convoy systems with long configurations (12PB, $13 \mathrm{~PB}, 23 \mathrm{~PB})$ require larger stopping distance \& time, tactical diameter, advance distance and transfer distance than those required for wide configuration (21PB, 31PB, 32PB).

K. K. King et al [5] continued his work to study the effect of shallow water on manoeuvring characteristics of pushed barge convoy systems. One pushed barge configuration (11PB) was taken as the subject of his study and the shallow water tests were conducted at Kyushu University. In the experiments, three different water depths to ship's draught ratios were performed. The results showed that, for different rudder angles, the largest turning circle occurs in deep water, followed by medium shallow and then shallow water. Therefore, the pushed barge convoy 11PB having a turning performance similar to wide beam vessel where turning trajectory decreases from deep to medium shallow to shallow water condition [5]. 


\subsection{Convoy resistance and powering calculation}

Several formulae exist for calculating the resistance and powering of seagoing ships. However, there is little in the literature concerning the calculation of the resistance and powering in rivers, specially pushed barge convoy systems navigating in waterway of somewhat limited cross section.

Resistance of a pushed barge convoy system depends on many geometrical and operational parameters such as: speed and draught of push boat, depth and width of the waterway, length and width of the barge train, and other indirect parameters related to the barge train.

Howe [6], Wang et al [7], Kaa [8] and Michalski [9] published their empirical methods. Some are based on a model test series that is not comprehensive, and some need additional data which are not easy to obtain in advance. Consequently, these inconveniences restrict the application of such methods.

An empirical method given by Marchal et al [10] may be used to estimate the resistance of a pushed barge convoy system; it had established a generalized relation between total resistance of pushed barge convoys and the geometrical characteristics of convoys and waterways. The range of application of this methodology given in Table 1 is relatively wide. The resistance of pushed barge convoy systems is estimated using Marchal's equation [10] after:

$$
\begin{aligned}
& \frac{R T}{\Delta}=\sum_{i=0}^{n_{1}} \sum_{j=0}^{n_{2}} \sum_{k=0}^{n_{3}} \sum_{l=0}^{n_{4}} \sum_{m=0}^{n_{5}} \sum_{n=0}^{n_{6}} \beta_{i j k l m n} \cdot\left(2 F n_{R h}\right)^{i} \cdot\left(10 F n_{L}\right)^{j} \cdot \\
& \left(\frac{M}{10}\right)^{k} \cdot\left(\frac{1}{10} \frac{B_{x}}{h-T_{x}}\right)^{l} \cdot\left(5 \frac{B_{x}}{B_{c}}\right)^{m} \cdot\left(2 \frac{T_{x}}{h}\right)^{n}
\end{aligned}
$$

Where, $\beta_{i j k l m n}$ is the coefficient of each term and the maximum exponents $n_{1}, n_{2}, n_{3}, n_{4}, n_{5}$, and $n_{6}$ of these six variables are $3,3,2,2,2$, and 1 in order of succession [10].

Table 1 Range of application of Marchal's method [10]

\begin{tabular}{|c|c|}
\hline Parameter & Range of application \\
\hline$F n_{R h}$ & $0-0.81$ \\
\hline$F n_{L}$ & $0-0.18$ \\
\hline$L_{x} / V_{x}{ }^{3}$ & $4.79-16.73$ \\
\hline$B_{x} / T_{x}$ & $3.5-28.5$ \\
\hline$B_{x} /\left(h-T_{x}\right)$ & $0.2-24.4$ \\
\hline$B_{x} / B_{c}$ & $0.063-0.48$ \\
\hline$T_{x} / h$ & $0.047-0.67$ \\
\hline$A_{x} / A_{c}$ & $0.0033-0.18$ \\
\hline
\end{tabular}

Unfortunately, no experimental work had been previously carried out to for river Nile vessels. Therefore, in this paper, the convenience of the range of application of Marchal's formula for Cairo-Aswan waterway is examined in order to adopt the approach to estimate the resistance of pushed barge convoy systems working through this waterway. 
Effective power $\left(P_{E}\right)$ can be calculated based on the calculated resistance of a pushed barge convoy and the desired service speed according to Eq. 2. Also, Eq. 3 can be used to calculate the required brake power $\left(P_{B}\right)$ for a push boat of pushed barge convoy system navigates at certain speed. Existing push boats have a propulsive efficiency $\left(\eta_{p}\right)$ varying from 0.30 to 0.45 [11]. It is obvious that, the value of the propulsive efficiency $\left(\eta_{p}\right)$ is difficult to estimate without sufficient experimental work, but for the purpose of comparison in this study, it may be adequately assumed to be of 0.4 .

$$
\begin{aligned}
& P_{E}=R_{T} \cdot V_{x} \\
& P_{B}=\frac{P_{E}}{\eta_{p}}
\end{aligned}
$$

\section{Cairo-Aswan waterway}

Cairo-Aswan waterway is a first class waterway with a length of $980 \mathrm{~km}$ and a minimum water depth of $2.5 \mathrm{~m}$ [12]. Fig. 2 shows Cairo-Aswan waterway. It connects all Upper Egypt Governorates from Aswan to Cairo and is used for cargoes, passengers and tourists transport. Also, it is wide enough to host traffic from South to North and vice versa. The distance from Aswan Dam to Delta Bridges is divided into four sections and contains 3 locks \& 21 bridges [12]. In the past, Assiut lock extremely affects the dimensions of Nile ships which navigate through Cairo-Aswan waterway. Recently, The Egyptian government is completely finished from the final stage of replacing and renovating the old Assiut lock by another one has a length of $160 \mathrm{~m}$ and width of $17 \mathrm{~m}$.

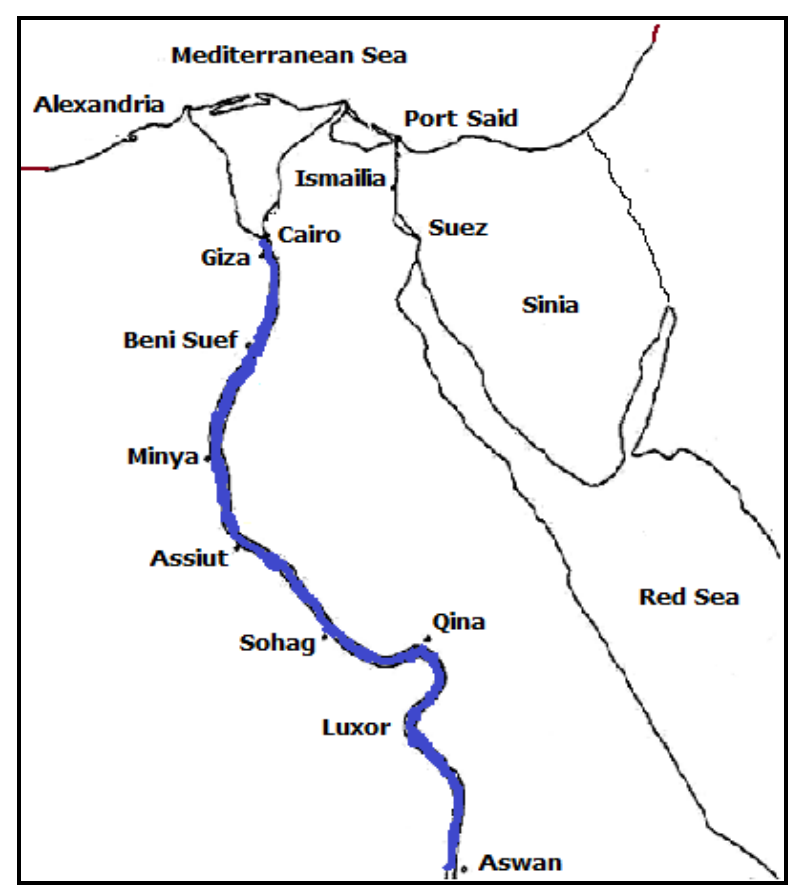

Fig. 2 Cairo-Aswan waterway

The right choice of ship's speed should be decided based on the Froude depth number to avoid the critical region of ship resistance. In this work the Froude depth number is taken equal to 0.7 [13]. Therefore, ship speed through Cairo-Aswan waterway must be less than $12.6 \mathrm{~km} / \mathrm{h}$. 


\section{Feasibility of pushed barge convoy in Cairo-Aswan waterway}

In this section, a comparison between the most economical configuration of pushed barge convoy and the existing river transport means is made to check the feasibility of using barge convoy system in Cairo-Aswan waterway. This comparison is carried out based on transport efficiency $\left(E_{T}\right)$ which is considered one of the most important technical and operating measures by which the cost of transport can be reduced and fleet made more competitive. $E_{T}$ can be defined as tons-kilometres per kilowatt-hour according to the following formula [14]:

$$
E_{T}=\frac{D w t \cdot V_{x}}{P_{B}}
$$

Eq. 4 shows that, it is not only the required power that is taken into account, but also the weight of the transported cargo and the time required to move that weight (service speed). Another comparison among three different configurations (12PB, 21PB and 22PB) of a pushed barge convoy system is made to find the most economical configuration of pushed barge convoy system working through Cairo-Aswan waterway. This procedure was carried out using a specially developed computer program, see Fig. 3.

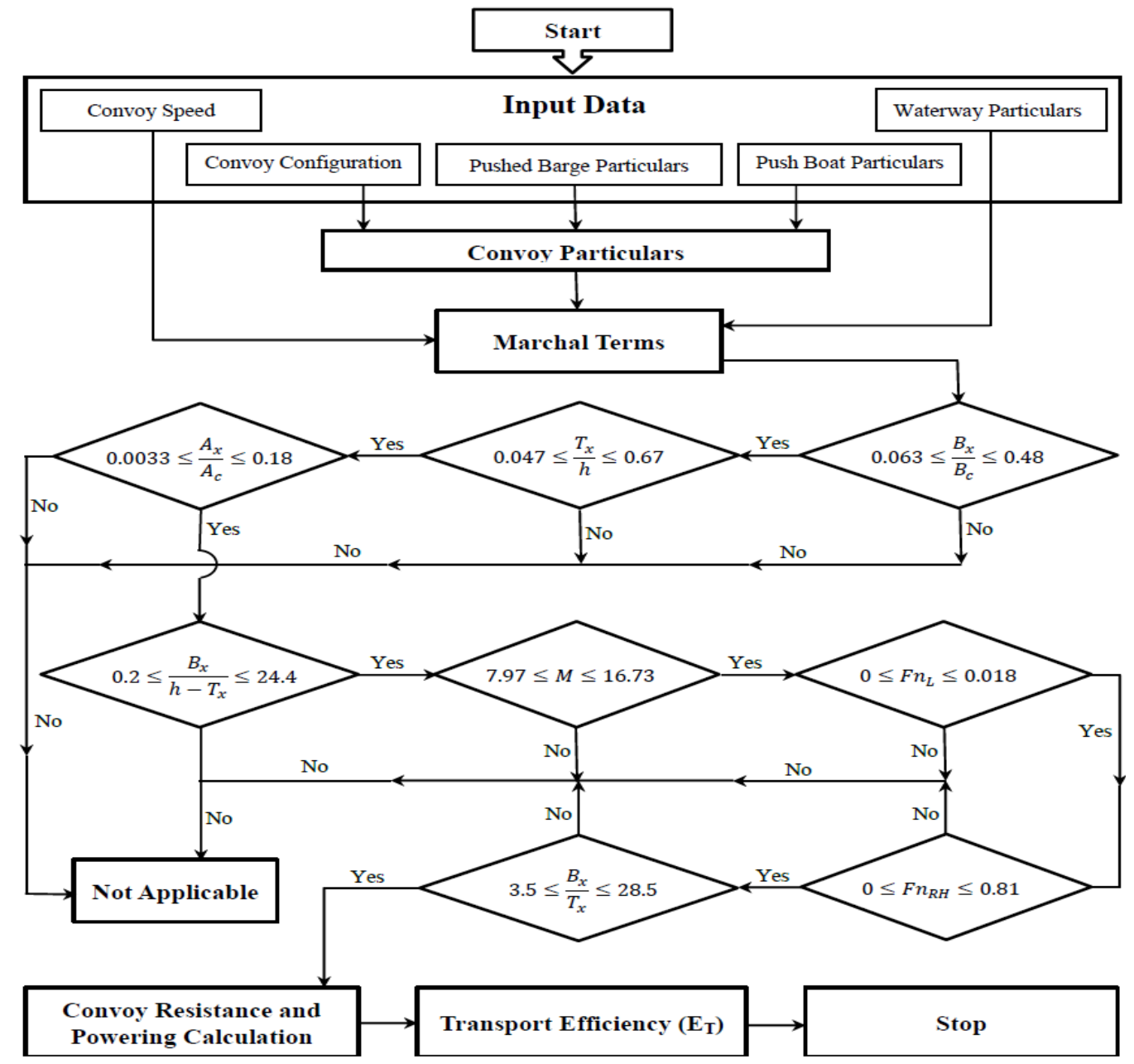

Fig. 3 Developed computer program

Pushed barges which are used in this application already exist in service and used in river transport through Cairo-Aswan waterway. Pushed barges and tug boat particulars are listed as shown in Table 2. 
Table 2 Particulars of the tug boat and pushed barges

\begin{tabular}{|c|c|c|}
\hline Items & Pushed Barges & Tug Boat \\
\hline Length & $50 \mathrm{~m}$ & $24 \mathrm{~m}$ \\
\hline Breadth & $7.5 \mathrm{~m}$ & $7.5 \mathrm{~m}$ \\
\hline Draft & $1.6 \mathrm{~m}$ & $1.2 \mathrm{~m}$ \\
\hline Block Coefficient & 0.88 & 0.6 \\
\hline Cargo Capacity & 425 tons & ----- \\
\hline
\end{tabular}

The convenience of Marchal's formula for Cairo-Aswan waterway is checked for three different configurations and illustrated in Table 3. The calculated values of the parameters of the configurations of the hypothetical pushed barge convoy system working through CairoAswan waterways conform compatible to the range of application of Marchal's formula as shown in Table 1.

Table 3 Adequacy of Marchal's formula for Cairo-Aswan waterway

\begin{tabular}{|c|c|c|c|}
\hline \multirow{2}{*}{ Parameter } & \multicolumn{3}{|c|}{ Convoy Configurations } \\
\cline { 2 - 4 } & $12 \mathrm{~PB}$ & $21 \mathrm{~PB}$ & $22 \mathrm{~PB}$ \\
\hline$F n_{R h}$ & 0.62 & 0.655 & 0.655 \\
\hline$F n_{L}$ & 0.08 & 0.103 & 0.080 \\
\hline$L_{x} / V_{x}{ }^{3}$ & 11.72 & 6.992 & 9.475 \\
\hline$B_{x} / T_{x}$ & 4.69 & 9.375 & 9.375 \\
\hline$B_{x} /\left(h-T_{x}\right)$ & 8.33 & 16.667 & 16.667 \\
\hline$B_{x} / B_{c}$ & 0.08 & 0.150 & 0.150 \\
\hline$T_{x} / h$ & 0.64 & 0.640 & 0.640 \\
\hline$A_{x} / A_{c}$ & 0.05 & 0.096 & 0.096 \\
\hline
\end{tabular}

\section{Results}

The developed computer program is used to calculate transport efficiency $\left(E_{T}\right)$ for pushed barge convoy system with three different configurations (12PB, 21PB and 22PB). The results are shown in Figs. 4 and 5.

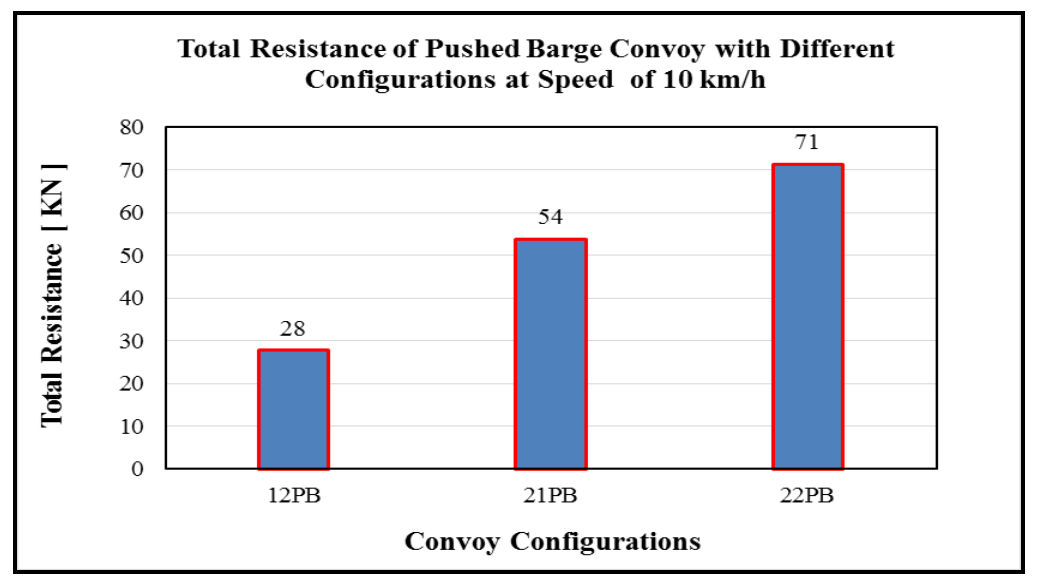

Fig. 4 Total resistance of pushed barge convoy 


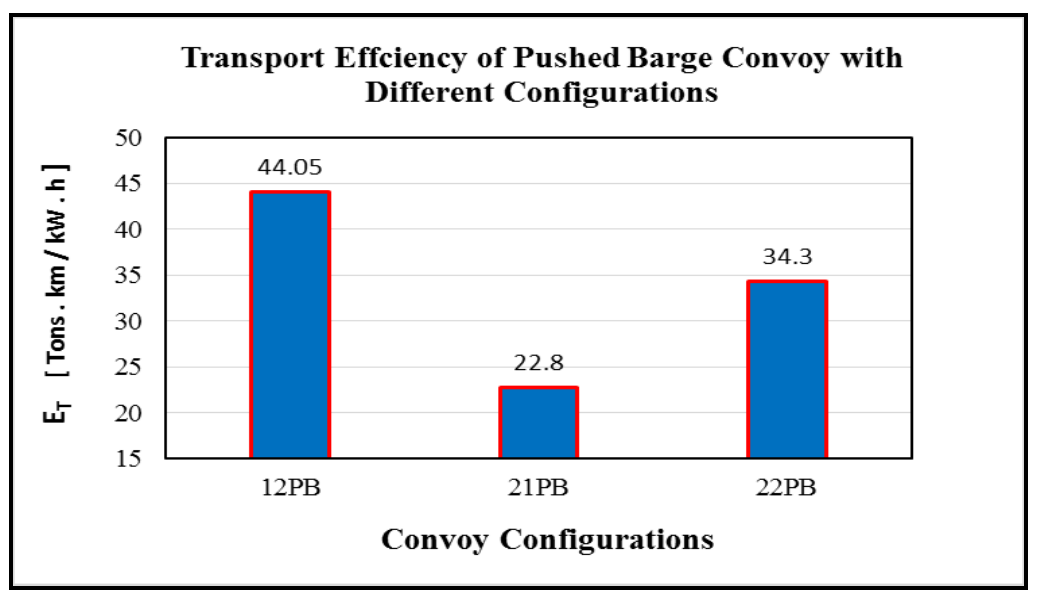

Fig. 5 Transport efficiency of pushed barge convoy

Fig. 4 shows that, in case of two pushed barge convoy, resistance of the wide configuration (21PB) is approximately double that of the long configuration (12PB). Also, Fig. 4 shows that resistance of four pushed barges convoy (22PB) is approximately 35\% higher than that of two pushed barge convoy in wide configuration (21PB). While, Fig. 5 shows that, in case of two pushed barge convoy, transport efficiency of the long configuration (12PB) is approximately double that of the wide configuration (21PB). Also, Fig. 5 shows that transport efficiency of two pushed barge convoy in long configuration (12PB) is approximately $29 \%$ higher than that of four pushed barges convoy (22PB).

The above mentioned results show that, in case of two pushed barge convoy, the long configuration (12PB) gives less resistance than the wide configuration (21PB). Although, four pushed barges convoy (22PB) gives the highest resistance, it gives higher transport efficiency than two pushed barge convoy in wide configuration (21PB). However, two pushed barges convoy in long configuration (12PB) gives the highest transport efficiency. Therefore, it can be said that $12 \mathrm{~PB}$ is the most economical configuration for a pushed barge convoy system working through Cairo-Aswan waterway.

Also, based on transport efficiency $\left(E_{T}\right)$, feasibility of using the pushed barge convoy system in rive Nile transport is checked by making a comparison between pushed barge convoy system and the existing means of inland transport in Egypt (self-propelled inland cargo ship and pusher barge - dump barge). Particulars of these means in are listed as shown in Table 4.

Table 4 Particulars of the existing means of inland transport in Egypt

\begin{tabular}{|c|c|c|c|}
\hline \multirow{2}{*}{ Items } & \multirow{2}{*}{$\begin{array}{c}\text { Self-propelled cargo } \\
\text { ship }\end{array}$} & \multicolumn{2}{|c|}{ Pusher barge - dump barge } \\
\cline { 3 - 4 } & $100 \mathrm{~m}$ & Pusher barge & Dump barge \\
\hline Length & $12 \mathrm{~m}$ & $7.4 \mathrm{~m}$ & $50 \mathrm{~m}$ \\
\hline Breadth & $2.3 \mathrm{~m}$ & $2.75 \mathrm{~m}$ & $7.4 \mathrm{~m}$ \\
\hline Depth & $1.6 \mathrm{~m}$ & $1.6 \mathrm{~m}$ & $2.75 \mathrm{~m}$ \\
\hline Draft & $12.96 \mathrm{~km} / \mathrm{h}$ & \multicolumn{2}{|c|}{$10 \mathrm{~km} / \mathrm{h}$} \\
\hline Speed & $1450 \mathrm{tons}$ & $360 \mathrm{tons}$ & $415 \mathrm{~m}$ \\
\hline Cargo Capacity & $600 \mathrm{hp}$ & $500 \mathrm{hp}$ & --- \\
\hline Brake Power & & \multicolumn{3}{|c|}{} \\
\hline
\end{tabular}


Fig. 6 shows results of the comparison between the most economical configuration of a pushed barge convoy system working through Cairo-Aswan waterway and the other inland transport means in Egypt. The results show that, pushed barge convoy system with 12PB configuration gives higher transport efficiency than self-propelled vessel and pusher barge dump barge. Therefore, it can be concluded that pushed barge convoy system is feasible for cargo transport through Cairo-Aswan waterway.

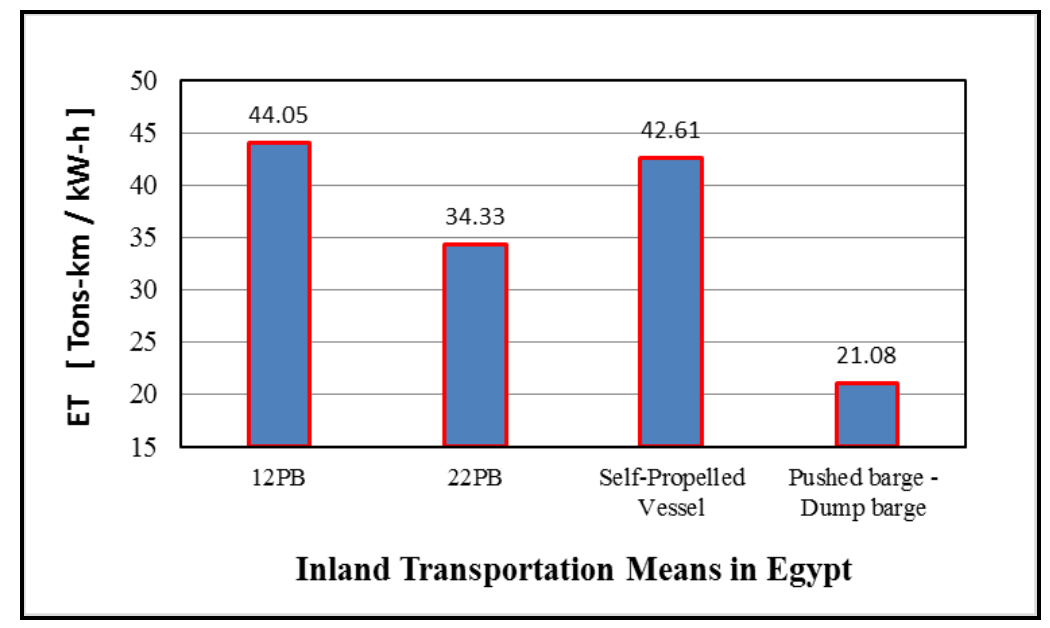

Fig. 6 Transport efficiency for inland transport means in Egypt

\section{Conclusions}

Convoy speed, cargo carrying capacity, number of barges and convoy configurations of any pushed barge convoy system working through Cairo-Aswan waterway are affected by the shallow water nature of the navigation route. Also, size of the existing locks represents another constraint on the characteristics of such system.

The pushed convoy system with long configuration gives higher tactical diameter, advanced distance, transfer distance, response time and stopping distance than the wide configuration. Also, the pushed barge convoy system with long configuration gives less resistance than the wide configuration.

The developed computer program represents a simple and accurate tool to calculate resistance and the required power for any configuration of a pushed barge convoy system works through Cairo-Aswan waterway. After some minor modifications, this program can be used for other inland waterways.

Based on the transport efficiency as a technical and operational measure, the most economical configuration of any pushed barge convoy system working through Cairo-Aswan waterway is two pushed barge convoy in the form of $12 \mathrm{~PB}$.

Transport efficiency of a pushed barge convoy system is higher than the other existing river transport means in Egypt. This means that, cargo transport by pushed barge convoy system working through Cairo-Aswan waterway is economically feasible.

The results of this study had been based on empirical formula, and their consistency with real cases still need to be further tested. Not only model tests may be exploited for such validation, but also numerical simulation based on computational fluid dynamics.

\section{REFERENCES}

[1] CI Capital Research Team: "Transport \& Logistics - Water Still Key to Egyptian Economic Health", CICR Egypt Book, December 2010. 
[2] K. K. King, H. Yasukawa, N. Hirata \& K. K. Kose: "Maneuvering simulations of pusher-barge systems", Journal of Marine Science and Technology, Volume 13, No. 2, May 2008. https://doi.org/10.1007/s00773-007-0267-4.

[3] K. Anuar: "Maneuvering Control for Pusher Barge in Inland Waterways", M. Sc. Thesis, Faculty of Mechanical Engineering, Universiti of Teknologi, Malaysia, 2008.

[4] E. V. Lewis: "Principles of Naval Architecture - Second Revision", the Society of Naval Architects and Marine Engineers, Vol. III, Jersey City, 1989.

[5] K. K. King, H. Yasukawa \& N. Hirata: "Shallow Water Effect on Turning Motion of a Pusher-Barge System", the 4th Asia-Pacific Workshop on Marine Hydrodynamics (APHydro 2008), Taipei, June 2008.

[6] C. W. Howe: "Mathematical Model for Barge Tow Performance", Journal of Waterway and Harbors Divisions, Proceeding of the American society of civil engineering, November 1976.

[7] C. Wang, J. Wang, G. LI, Y. Yan, B. Wang \& Y. Xu: "On The Trend Towards the Development of Push Train of The Lower Chanjiang River in Near Future", Transaction of The Chinese Society of Naval Architecture and Marine Engineering, No. 74, July 1981.

[8] E. Kaa: "Power and speed of push tows in canals", Symposium on Aspects of Navigability of Constraint Waterways Including Harbour Entrances, Delft, 1981.

[9] J. P. Michalski: "A method of predicting Main Propulsion Power for Inland waterways push trains", Polish Maritime Research, 2006.

[10] J. L. J. Marchal, Y. D. Shen \& D. Kicheva: “An Empirical Formula to Estimate the Resistance of a Convoy in Restricted Water Way”, Journal of Ship Research, Vol. 40, No. 2, June 1996.

[11] A. Zoran, \& J. Marija: "Improving Inland Waterway Transport Efficiency by a New Approach to Vessel Design”, European Inland Waterway Navigation Conference, Hungary, 2005.

[12] The River Transport Authority (RTA): “Inland Navigation Guide for River Nile”, Egypt, 2015.

[13] M. M. Moustafa: "Optimization Procedure for Preliminary Design Stage of Cairo-Damietta SelfPropelled Grain Bulk Ships”, Brodogradnja, Volume 66, No. 4, Croatia, 2015.

[14] A. Radonjić: "Strategy to Reduce Pollution from Serbian Pushboat", International Journal for Traffic and Transport Engineering, Vol. 1, No. 2, 2011.

\section{NOMENCLATURES}

$\begin{array}{ll}A_{c} & \text { Cross-section area of the waterway, } \mathrm{m}^{2} \\ A_{x} & \text { Cross-section area of the convoy, } \mathrm{m}^{2} \\ B_{c} & \text { Width of the waterway, m } \\ B_{x} & \text { Breadth of the convoy, m } \\ D w t & \text { Deadweight of the convoy, tons } \\ E_{T} & \text { Transport efficiency, tons. km/(kW. h) } \\ F n_{L} & \text { Froude number } \\ F n_{R h} & \text { Froude number defined in terms of the hydraulic radius } \\ h & \text { Water depth, m } \\ M & \text { Length }- \text { displacement ratio of the convoy } \\ P_{B} & \text { Brake power, } \mathrm{kW} \\ P_{E} & \text { Effective power, } \mathrm{kW} \\ R_{h} & \text { Hydraulic radius, } \mathrm{m} \\ R_{T} & \text { Total Resistance, } \mathrm{KN} \\ T_{x} & \text { Draft of the convoy, m } \\ V_{x} & \text { Convoy speed, km/hr }\end{array}$


The Most Economical Configuration of Pushed Barge Convoy System Through Cairo-Aswan Waterway
S. M. Shenouda, M. M. Moustafa, H. S. El-Kilani, L. B. Kamar

$\Delta \quad$ Displacement of the convoy, tons

$\eta_{P} \quad$ Propulsive efficiency

Submitted: $\quad$ 16.11.2017. S. M. Shenouda, shenoudamaher@ymail.com

Accepted: $\quad$ 19.01.2018. Suez Canal Authority, Ismailia, Egypt.

M. M. Moustafa, sasa3875@yahoo.com

Naval Architecture and Marine Engineering Department, Faculty of Engineering, Port Said University, Port Fuad, Egypt.

H. S. El-Kilani, hebaelkilani@gmail.com

Naval Architecture and Marine Engineering Department, Faculty of Engineering, Port Said University, Port Fuad, Egypt.

L. B. Kamar, kamar_laila@ hotmail.com

Naval Architecture and Marine Engineering Department, Faculty of Engineering, Port Said University, Port Fuad, Egypt. 